\title{
THE SIDE-EFFECT OF ORGANIC INSECTICIDE SPINOSAD ON BIOCHEMICAL AND MICROBIOLOGICAL PROPERTIES OF CLAY SOIL
}

\author{
Arkadiusz Telesiński' ${ }^{1}$ Wiera Michalcewicz' ${ }^{2}$, Maciej Płatkowski ${ }^{1}$, Michał Stręk' ${ }^{1}$ \\ Mirosław Onyszko', Jolanta Wiśniewska ${ }^{3}$
}

1 Department of Plant Physiology and Biochemistry, West Pomeranian University of Technology, Słowackiego 17, 71-434 Szczecin, Poland, e-mail: arkadiusz.telesinski@zut.edu.pl

2 Department of Microbiology and Environmental Biotechnology, West Pomeranian University of Technology, Słowackiego 17, 71-434 Szczecin, Poland

3 Department of Soil Science, Grassland and Environmental Chemistry, West Pomeranian University of Technology, Słowackiego 17, 71-434 Szczecin, Poland

Received: 2015.06 .06 Accepted: 2015.08.31 Published: 2015.10.01

\begin{abstract}
The aim of the study was to determine the effect of spinosad on soil biochemical and microbiological properties. The experiment was carried out on sandy loam with $\mathrm{C}_{\text {org }}$ content $10.91 \mathrm{~g} \cdot \mathrm{kg}^{-1}$. Spinosad, as Spintor $240 \mathrm{SC}$ was added into soil in dosages: a recommended field dosage, and fivefold, tenfold, and twenty-fivefold higher dosages. The amount of spinosad introduced into soil was between 12.55 and $313.75 \mathrm{~g} \cdot \mathrm{kg}^{-1}$. Moreover, soil samples without spinosad supplement were prepared as a reference. Respective Spintor 240 SC doses were converted into $1 \mathrm{~kg}$ soil, taking into account 10 $\mathrm{cm}$ depth. After application of insecticide water emulsions, soil moisture was brought to $60 \%$ maximum holding water capacity. The soil was thoroughly mixed and stored in tightly-closed polyethylene bags at $20^{\circ} \mathrm{C}$ for a period 4 weeks. During the experiment dissipation of spinosad, soil enzymes (dehydrogenase, alkaline phosphatase, acid phosphatase, urease) and number of bacteria, fungi, actinomycetes were assayed. Obtained results showed, that dissipation of spinosad in soil was relatively fast - the DT50 of this insecticide was ranged between 1.11 and 2.21 days. Spinosad residues had different effects on soil microbiological and biochemical properties. However, over time the impact of this insecticide definitely decreased. This indicated that the use of spinosad in organic farming, particularly in the field dosage, does not pose a long-term threat to the soil environment.
\end{abstract}

Keywords: clay soil, spinosad, soil environment.

\section{INTRODUCTION}

The continuous search for pest control products with acceptable environmental profiles has renewed scientific interest in naturally occurring bioactive metabolites from microbial and higher plant sources [Pillmoor et al,. 1993]. Although such compounds tend to be water soluble, easily metabolized and non-bioaccumulatory, biogenic sourcing does not necessarily confer environmental acceptability [Thompson et al., 2000]. Therefore, assessment of environmental persistence, fate and toxicological properties, including stud- ies, is necessary for these compounds [Thompson et al., 2002].

Spinosad is a biologically derived insecticide which consists of two compounds: spinosyn A and D. The compounds are macrolides and contain a unique tetracyclic ring system to which two different sugars are attached [Sharma et al., 2007]. These compounds were isolated from the soil actinomycetes Saccharopolyspora spinosa [Kowalska and Drozdzyński, 2009]. Spinosad possesses both contact and stomach poison activity against insects belonging to Coleoptera, Diptera, Hymenoptera, Isoptera, Lepidoptera, 
Siphonoptera and Thysanoptera but has little or no activity against sucking insects, predatory insects and mites [Elzen, 2001; Galvan et a1., 2006; Elliot et al., 2007]. It is a neurotoxin with a novel mode of action involving the nicotinic acetylcholine receptor and apparently the GABA receptors as well [Cisneros et al., 2002].

Spinosad is registered in many countries for use on a variety of crops, including cotton, corn, soybean, fruits and vegetables [West et al., 2000]. It shows minimal acute toxicity $\left(\mathrm{LD}_{50}\right.$ (rats) $\left.>5000 \mathrm{mg} \cdot \mathrm{kg}^{-1}\right)$, is non-carcinogenic, non-mutagenic and non-neurotoxic in mammalian test animals [Thompson et al., 2002] and also has a favourable environmental profile as it does not leach, bioaccumulate, volatilize or persist in the environment [Sharma et al., 2007]. Laboratory and field studies demonstrate that spinosad may undergo different abiotic and biotic degradation in soils [Thompson et al., 2002].

The occurrence of spinosad and other pesticides can interference on soil biological properties affecting the soil fertility. Since the soil enzymes involved in nutrient mineralization and organic matter degradation are mostly of microbial origin. The response of soil microorganisms to the presence of pesticides is of particular interest [Perucci et al., 1999].

The study aims at determining the effect of spinosad on biochemical and microbiological properties of soil.

\section{MATERIAL AND METHODS}

Top soil (up to $10 \mathrm{~cm}$ depth) samples were collected from Gumięniecka Plain (53 $24^{\prime}$ N $\mathrm{N}$ and $14^{\circ} 28^{\prime} \mathrm{E}$ ), with no prior pesticide treatment. The soil samples were sieved through a $2.0 \mathrm{~mm}$ mesh size to remove stones and plant debris. The soil was classified as sandy loam (43\% fraction $1.0-$ $0.1 \mathrm{~mm}, 30 \%$ fraction $0.1-0.02 \mathrm{~mm}, 20 \%$ fraction $<0.02 \mathrm{~mm}$ ). Some of its physical and chemical characteristics as follows: $\mathrm{pH} 6.8$, organic $\mathrm{C} 10.91$ g.kg-1 ${ }^{-1}$ total N $1.39 \mathrm{~g} \cdot \mathrm{kg}^{-1}$, TEB $13.4 \mathrm{crnol}(+) \cdot \mathrm{kg}^{-1}$, CEC $11.8 \mathrm{crnol}(+) \cdot \mathrm{kg}^{-1}$.

The soil was divided into $1 \mathrm{~kg}$ weighed samples, thereafter introducing into it water emulsions of insecticide Spintor 240 SC (240 g of spinosad in $1 \mathrm{dm}^{3}$ preparation) in the following doses: a recommended field dose (FD), a fivefold higher dose (5FD), tenfold higher dose (10FD) and one twenty-fivefold higher dose (25FD). Moreover, soil samples without spinosad supplement were prepared as a reference.

Respective doses of Spintor 240 SC were converted into $1 \mathrm{~kg}$ soil, taking into account 10 cm depth, and are presented in Table 1. After application of insecticide to water emulsions, soil moisture was brought to $60 \%$ maximum soil water capacity. The soil was thoroughly mixed and stored in tightly-closed polyethylene bags at $20^{\circ} \mathrm{C}$ for a period of 4 weeks.

Table 1. Amount of spinosad added into soil $\left(\mathrm{mg} \cdot \mathrm{kg}^{-1}\right)$

\begin{tabular}{|c|c|c|c|}
\hline FD & 5FD & 10FD & 25FD \\
\hline 12.55 & 62.75 & 125.50 & 313.75 \\
\hline
\end{tabular}

Spinosad residues, as a sum of spinosyn A and spinosyn $\mathrm{D}$, on day 0 (1 $\mathrm{hr}$ after application), 1, 3, $7,14,28$, were determined, by high performance liquid chromatography (HPLC, a Perkin Elemer model Series 200) equipped with UV detector $(250 \mathrm{~nm})$. following the technique as described by Sharma et al. [2007] inclusive of purification by solid-phase extraction with silica SPE cartridges. The column used was C18 (250 mm x $4.6 \mathrm{~mm}$ i.d). The mobile phase was acetonitrile:methanol:2\% ammonium acetate $(21: 21: 8 \mathrm{v} / \mathrm{v} / \mathrm{v})$ at a flow rate of $2.0 \mathrm{~cm}^{3} \mathrm{~min}^{-1}$. A $5 \mathrm{~mm}^{3}$ aliquot of each sample was injected each time for residue analysis. The representative retention times of spinosyn $\mathrm{A}$ and $\mathrm{D}$ were $9.3 \mathrm{~min}$ and $10.6 \mathrm{~min}$, respectively.

Soil enzyme activity: dehydrogenase, urease, and acid and alkaline phosphatase, were determined by spectrophotometric methods (Shimadzu, model UV-1800), on the same days, as spinosad residues.

Soil alkaline and acid phosphatase activity was determined by measuring the p-nitrophenol released after incubation of the properly buffered soil with p-nitrophenyl phosphate as substrate [Tabatabai and Bremner, 1969]. Soil dehydrogenase activity (DHA) was determined according to Thalmann [1968] by using 2,3,5-triphenyltetrazolium chloride as an electron acceptor and Tris$\mathrm{HCl}$ buffer at $\mathrm{pH}$ 7.4. Soil urease activity was determined according to Kandeler and Gerber [1988] by monitoring the release of ammonium from soil treated with urea as substrate and incubated with borate buffer at $\mathrm{pH} 10.0$.

On day $0(1 \mathrm{hr}), 7$ and 28 , the main groups of soil microorganisms were determined. The number of microorganisms was determined by a technique of soil serial dilution plate culture. The 
total number of bacteria was determined on Bunt and Rovira culture medium [Bunt and Rovira, 1955], total number of fungi was determined on the Martin rose bengal culture medium [Martin 1950], and total number of actinomycetes was determined on Gypsies starch-ammonia culture medium [Cyganov et al., 1964].

\section{RESULTS AND DISCUSSION}

The percent recovery values of spinosad form soil samples were found to be about $97 \%$ and its residues declined consistently with time (Figure 1). Calculated DT50 estimates for spinosad ranged from 1.11 to 2.21 days, and depends on insecticide dosage (Table 2). Sharma et al. [2007] reported that the DT50 values of spinosad in soil were 1.45-2.63 days. Under field conditions spinosad dissipates rapidly from soil surfaces with observed DT50 of less than 1 day. However, spinosad present in deeper soils or shaded soils has been reported to degrade slowly with a DT50 of 9-17 days. Very short half-lives values $(<1$ day) for spinosad was observed in agricultural soils of the southern USA [Hale and Portwood, 1996]. Thompson et al. [2002], found that spinosad is quickly metabolized by soil microorganisms under aerobic condition, however, under anaerobic conditions, the degradation is slower. The results obtained by Gębala and Mickiewicz [2012] shown that spinosad is not ready biodegradable in water and not toxic to microbial inoculum.

The effects of spinosad on the activities of dehydrogenase, acid phosphatase, alkaline phosphatase, and urease are depicted in Figure 2. Compared with control, dehydrogenase activity decreased significantly, from day 1 to day 28 , after treatment of spinosad in dosages 10FD
Table 2. Half-lives (DT50) of spinosad in soil (days)

\begin{tabular}{|c|c|c|c|}
\hline FD & 5FD & 10FD & 25FD \\
\hline 1.11 & 1.37 & 1.91 & 2.21 \\
\hline
\end{tabular}

and 25FD (Figure 2A). The activity of alkaline phosphatase did not significantly change during the time of experiment (Figure 2B). Significant decrease of acid phosphatase was observed in soil treated with spinosad in dosage 10FD on days 1 and 3 , and in soil treated with insecticide in dosage 25FD on days 1, 3, 7 and 14 (Figure 2C). Urease activity in soil was significantly inhibited after the application of all spinosad dosages on day 1 , and this insecticide in dosages FD, 5FD and 10FD on day 3 (Figure 2D). Results obtained by Telesiński and Płatkowski [2012] shown stimulation of o-diphenol oxidase activity in sandy loam and inhibition of this enzyme activity after spinosad treatments. Mohiddin et al. [2015] reported, that spinosad was stimulatory to the activities of cellulase, invertase and amylase at low concentrations $\left(2.5 \mathrm{~kg} \mathrm{ha}^{-1}\right)$ at 10-day interval. Overall, the higher concentrations $(5.0-10.0 \mathrm{~kg}$ $\mathrm{ha}^{-1}$ ) of spinosad were toxic or innocuous to cellulase, invertase and amylase activity.

Dehydrogenases occur intracellularly in all microbial cells and it is linked with microbial respiratory processes. Phosphatases and urease are of particular importance on account of their role in the soil phosphorus and nitrogen cycle, respectively [Hussain et al., 2009]. Many authors shown inhibitory or stimulatory effects of different insecticides on the activity of these enzymes [Madhuri and Rangaswamy, 2002; Antonious, 2003; Xie et al., 2004; Menon et al., 2005; Mayanglambam et al., 2005]

The results of quantitative analyses of the population of soil microbial community are shown in

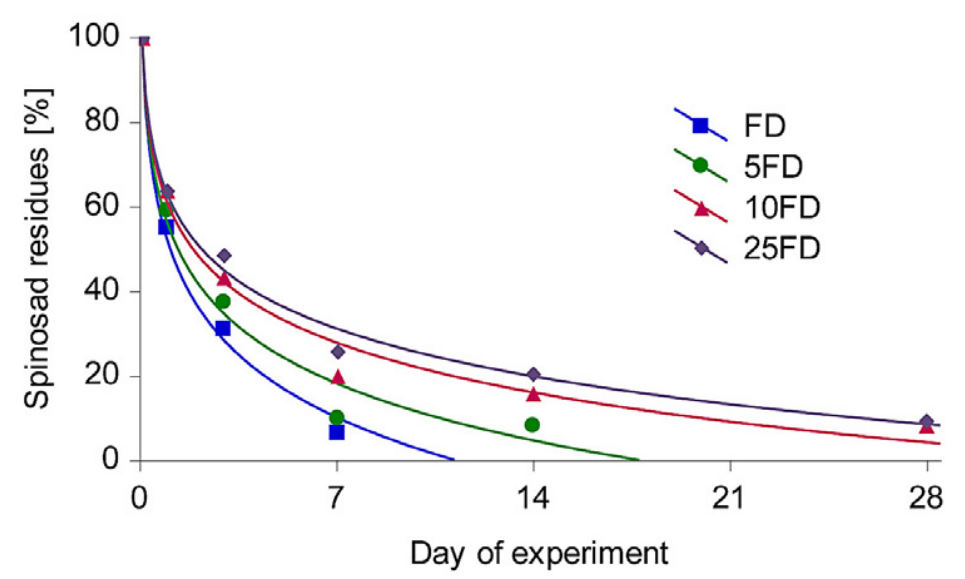

Figure 1. The logarithmic curves of spinosad dissipation in soil 
A

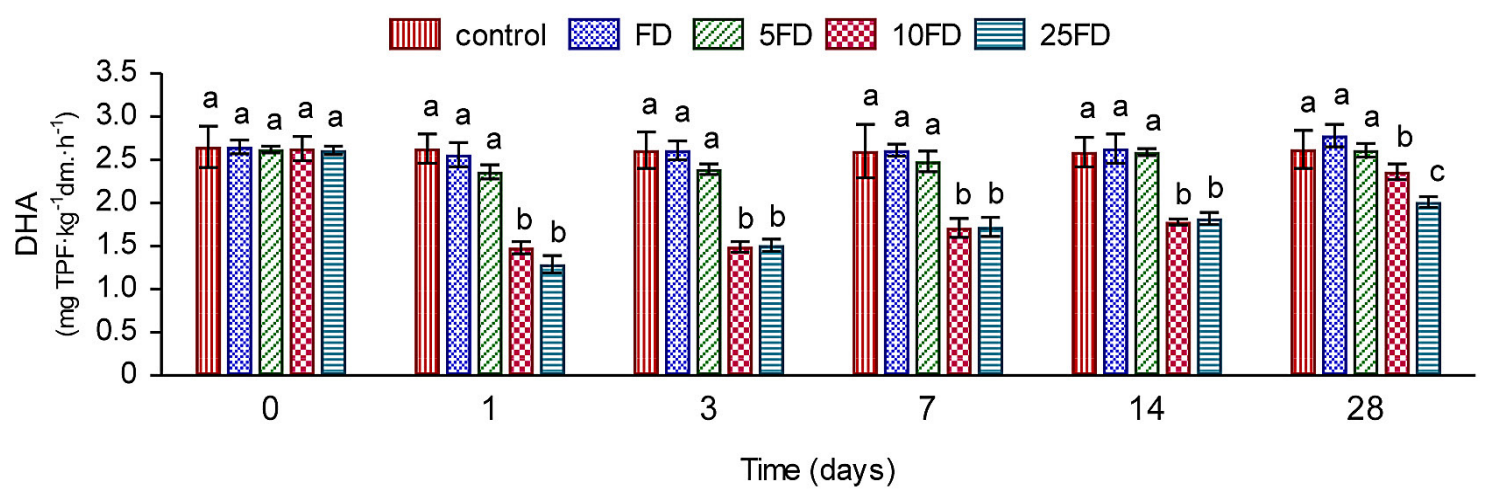

B

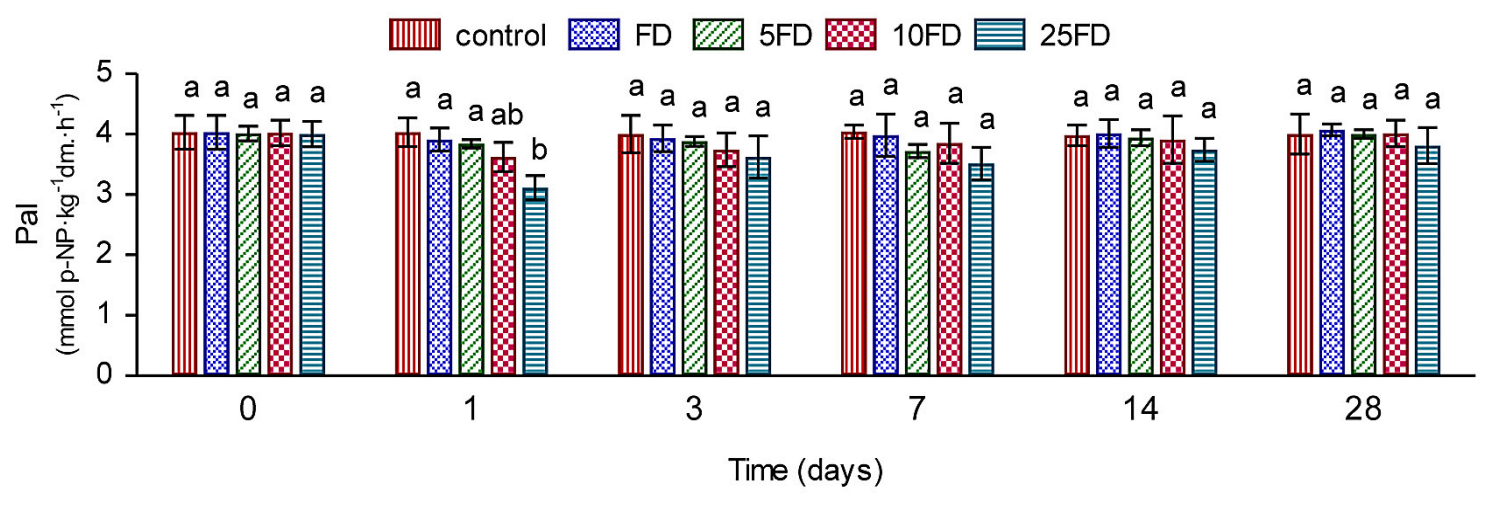

C

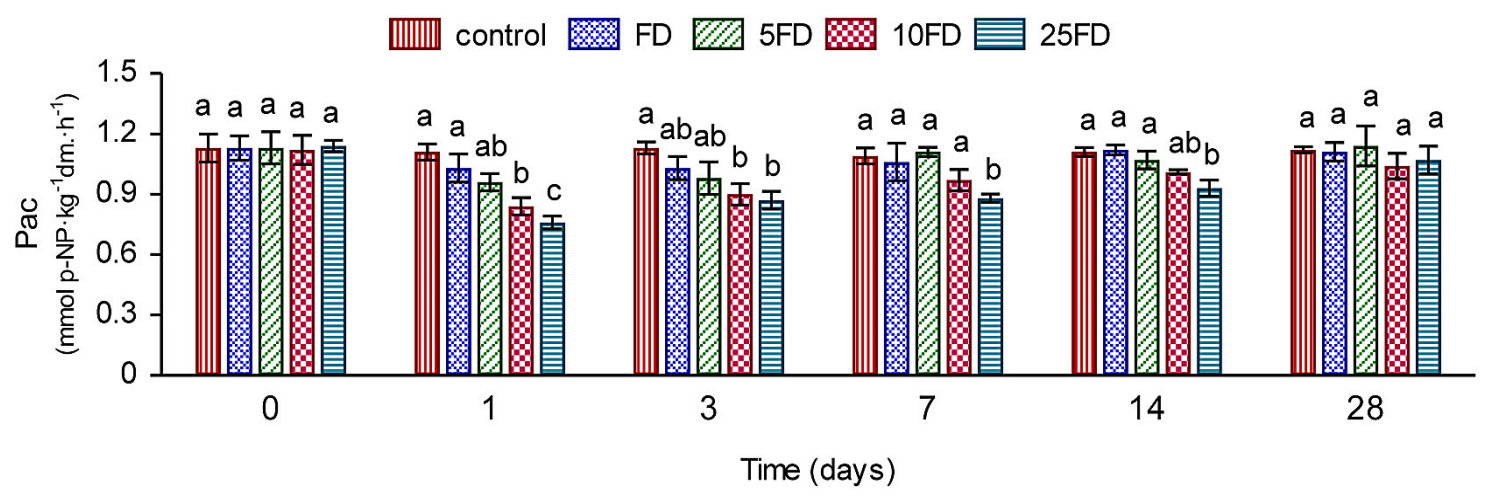

D

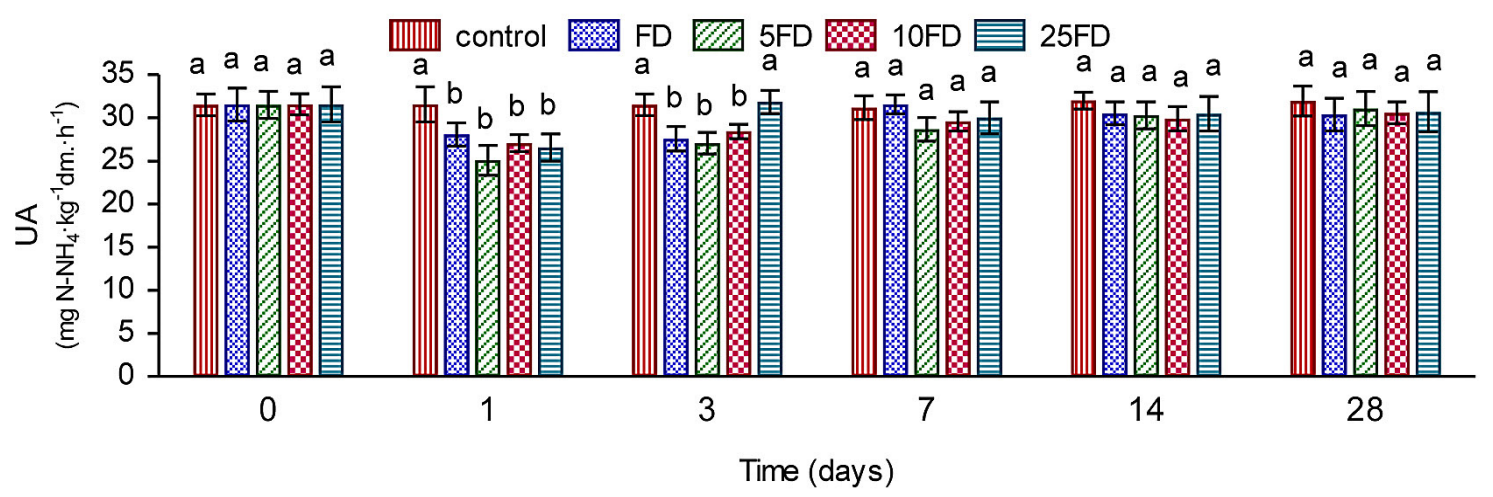

Figure 2. Effect of spinosad on dehydrogenase (A), alkaline phosphatase (B), acid phosphatase (C) and urease (D) activity in soil 
A

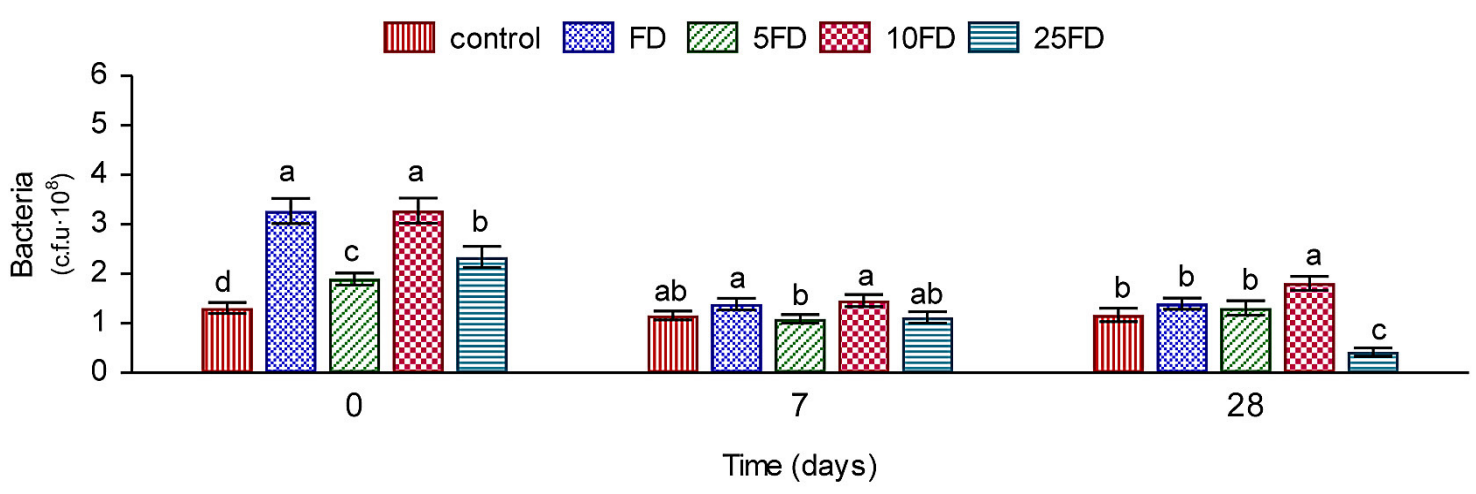

B

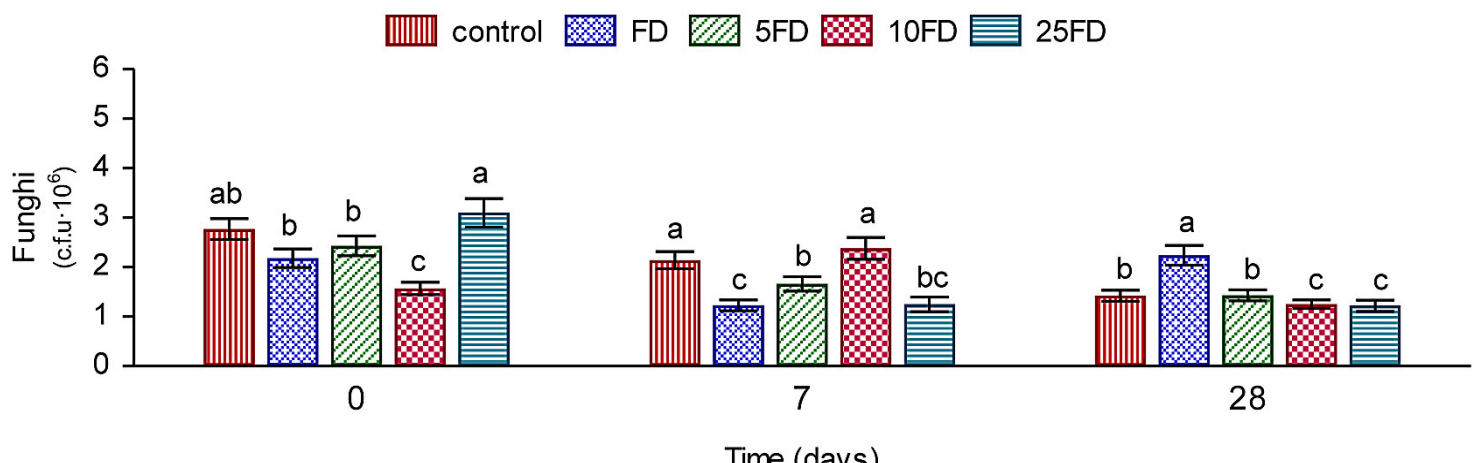

C

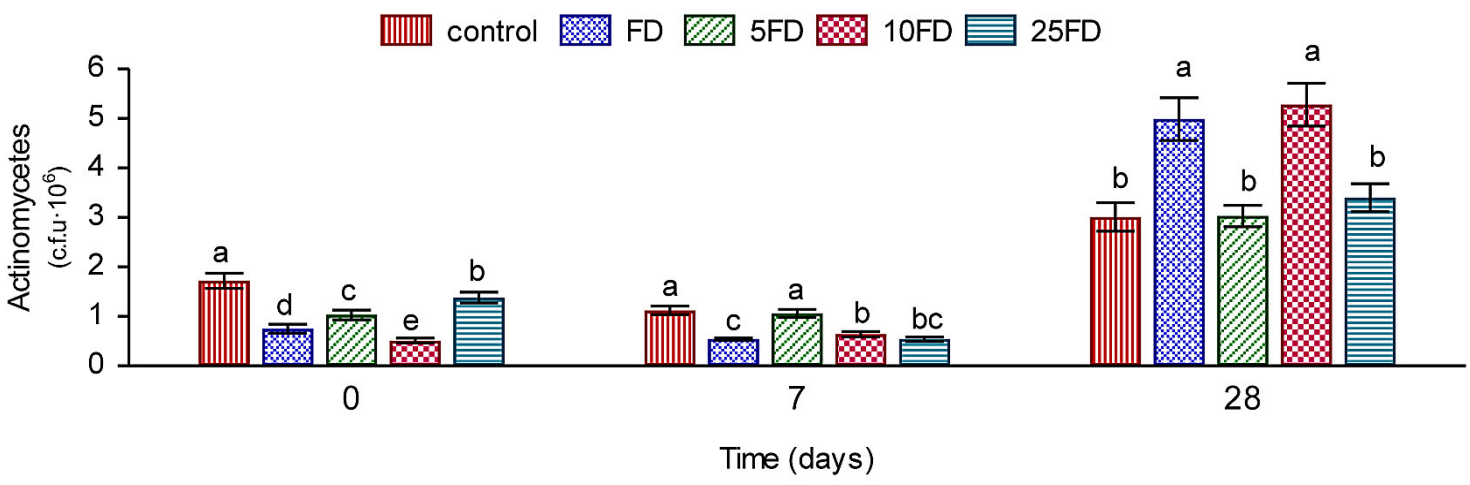

Figure 3. The effęct of spinosad on the number of bacteria (A), fungi (B) and actinomycetes (C) in soil

Figure 3. The number of bacteria in soil spiked with all dosages of spinosad increased significantly compared with control on day 1 . On day 7 the number of bacteria gradually recovered to the control. Although, on day 28 in soil treated with spinosad on dosage 10FD, and 25FD the number of bacteria increased and decreased, respectively (Figure 3A).

The cultivable number of fungi on day 1 , significantly decreased only after treatments of spinosad on dosage IOFD. on day 7 , the significant inhibition of fungi number was observed in soil with spinosad in dosages FD, 5FD and 25FD, while on day 28 the application of spinosad in dosage FD significantly increased, and in dosage 10FD and 25FD decreased (Figure 3B).

The number of actinomycetes was significantly decreased on day I in soil treated with spinosad in all dosages, and on day 7 in soil with insecticide in dosages FD, 10FD and 25FD. However, on day 28 the number of actinomycetes was the highest, and spinosad in dosages FD and 10 FD caused increase of actinomycestes number (Figure 3C).

Some insecticides stimulated the growth of microorganism population, but other insecticides 
have depressive effects or no effects on microorganisms. An increase of the number of bacterial population was observed in soil treated with bifenthrin [Ahmed and Ahmad, 2006], isofenphos [Digrak and Kazanici, 2001] and carbofuran [Lo, 2010]. Digrak and Kazanici [2001] observed that the treatments of organophosphorus insecticides: isofenphos, phorate and fonofos had no side-effect on the development of the number of actinomycetes and fungi. Chen et al. [2014)] reported the inhibitory effect of chlorpyrifos on the population of soil microorganism. Similar impact was observed for cypermthrin [Ahmed and Ahmad, 2006] and endosulfan [Nasim et al. 2005]. Moreover, the biodegradation of some insecticides (phorate, carbofuran and fęnvalerate) stimulated the growth and activity of heterohophic microorganisms which favour the mineralization of organic matter and biological transformation of other plant nutrients in soil to derive energy, carbon and other elements for microbial metabolism for their cellular constituents, resulting in lower retention of organic $\mathrm{C}$ in soil [Das and Mukherjee, 2000; Hussain et a1., 2009).

\section{CONCLUSIONS}

1. Dissipation of spinosad in soil was relatively fast - the half-life of this insecticide was ranged between 1.11 and 2.21 days.

2. Spinosad residues had different effects on soil microbiological and biochemical properties. However, over time the impact of this insecticide definitely decreased.

3. The obtained results showed that the use of spinosad in organic farming, particularly in the field dosage does not pose a long-term threat to the soil environment.

\section{REFERENCES}

1. Ahmed S., Ahmad M.S. 2006. Effect of insecticides on total number of soil bacteria under laborarory and field condition. Pak. Entomol. 28(2), 63-67.

2. Antonious G.F. 2003. Impact of soil management and two botanical insecticides on urease and invertase activity. J. Environ. Sci. Health B 38(4), 478-488.

3. Bunt J.S., Rovira A.D. 1955. Microbiological studies of some subantarctic soil. J. Soil Sci. 6, 119-128.

4. Chen L.Z., Li Y.L., Yu Y.L. 2014. Soil bacterial and fungal community succession under the stress of chlorpyrifos application and molecular characterization of chlorpyrifos-degrading isolates using ERICPCR. J. Zhejiang Univ. Sci. B. 15(4), 320-332.

5. Cisneros J., Goulson D., Derwent L.C., Penagos D.I., Hemandez O., Williams T. 2002. Toxic effects of spinosad on predatory insects. Biol. Contr. 3, 156-163.

6. Cyganov V.A., Zukov R.A., Timofejeva K.A. 1964. Morfologobiochimiciskie osobennosti novovo vida aktinomiceta 27321. Mikrobiologija 33(5), 863-869.

7. Das A.C., Mukherjee D. 2000. Soil application of insecticides influences microorganisms and plant nutrients. Appl. Soil Ecol. 14, 55-62.

8. Digrak M., Kazanici F. 2001. Effect of some organophosphorus insecticides on soil microorganisms. Turk. J. Biol. 25, 51-58

9. Elliot R., Benjamin M., Gillott C. 2007. Laboratory studies of the toxicity of spinosad and deltamethrin to Phyllotreta cruciferae (Coleoptera; Chrysomelidae). Can. Entomol. 139(4), 534-544.

10. Elzen G.W. 2001. Lethal and sublethal effects of insecticide residues on Orius insidiosus (Hemiptera: Anthocoridae) and Geocoris punctipes (Hemiptera; Lygaeidae). J. Econ. Entomol. 94(1), 55-59.

11. Galvan T.L., Koch R.L., Hutchison W.D. 2006. Toxicity of indoxacarb and spinosad to the multicolored Asian lady beetle, Harmonia axyridis, via three routes of exposure. Pest Manag. Sci. 62, 797-804.

12. Gębala P., Mickiewicz A. 2012. Spinosad - ready biodegradability test in water. J. Ecol. Health 16(2), 55-60.

13. Hale K.A., Portwood D.E. 1996. The aerobic soil degradation of spinosad - a novel natural insect control agent. J. Environ Sci. Health B 31, 477-484.

14. Hussain S., Siddique T., Saleem M., Arshad M., Khalid A. 2009. Impact of pesticides on soil microbial diversity, enzymes, and biochemical reactions. Adv. Agron. 102, 159-200.

15. Kandeler E., Gerber H. 1988. Short-term assay of soil urease activity using colorimetric determination of ammonium. Biol. Fertil. Soils 6(1), 68-72.

16. Kowalska I., Drożdżyński D. 2009. Spinosad as insecticide in organic farming - possibilities of using and monitoring of residues. Proc. ECOpole. $3,71-75$.

17. Lo C.C. 2010. Effect of pesticides on soil microbial community. J Environ. Sci. Health B 45(5), 348-359.

18. Madhuri R.J., Rangaswamy Y. 2002. Influence of selected insecticides on phosphatase activity in groundnut (Arachis hypogeae L.) soils. J. Environ. Biol. 23(4), 393-397.

19. Martin J.P. 1950. Use of amid, rose bengale and streptomycin in the plate method for estimating soil fungi. Soil Sci. 69, 215-232. 
20. Mayanglambam T., Vig K., Singh D.K. 2005. Quinalphos persistence and leaching under field conditions and effects of residues on dehydrogenase and alkaline phosphomonoesterases activities in soil. Bull. Environ. Contam. Toxicol. 75, 1067-1076.

21. Menon P., Gopal M., Parsad R. 2005. Effects of chlorpyrifos and quinalophos on dehydrogenase activities and reduction of $\mathrm{Fe}^{3+}$ in the soils of two semi-arid fields of tropical India. Agric. Ecosyst. Environ. 108, 73-83.

22. Mohiddin G.J., Srinivasulu M., Subramanyam K., Madakka M., Meghana D., Rangaswamy Y. 2015. Influence of insecticides flubendiamide and spinosad on biological activities in tropical black and red clay soils. Biotech. 5(1), 13-21.

23. Nasim G., Ilyas N., Shabbir A. 2005. Study of effect of organic pesticides: endosulfan and bifenthrin on growth of some soil fungi. Mycopathol. 3(1-2), 27-31.

24. Perucci P., Vischietti C., Battistioni F.1999. Rimsulfuron in a silty clay loam soil: Effect upon microbiological microcosm conditions. Soil Biol., Biochem. 31, 195-204.

25. Pillmoor J.B., Wright K., Teny A.S. 1993. Natural products as a source of agrochemicals and leads for chemical synthesis. Pest. Sci. 39(2), 131-140.

26. Sharma A., Srivastava A., Ram B., Srivastava P.C. 2007. Dissipation behaviour of spinosad insecticide in soil, cabbage and cauliflower under subtropical conditions. Pest Manag. Sci. 63, 1141-1145.

27. Tabatabai M.A., Bremner J.M. 1969. Use of pnitrophenyl phosphate for assay soil phosphatase activity. Soil Biol. Biochem. 1(4), 307-310.

28. Thalmann A. 1968. Zur Methodik der Bestimmund der Dehydrogenaseaktivitat im Boden mittęls Triphenyltetrazoliumchlorid (TTC). Landwirt. Forsch. 21, 249-258.

29. Thompson G.D., Dutton R., Sparks T. 2000. Spinosad a case study: an example from a natural products discovery program. Pest Manag. Sci. 56, 696-702.

30. Thompson D.G., Harris B.J., Buscarini T.M., Chartrand D.T. 2002. Fate of spinosad in litter and soils of a white spruce plantation in central ontario. Pest Manag. Sci. 58, 397-404.

31. Telesiński A., Płatkowski M. 2012. Assessment of side-effect of spinosad on o-diphenol oxidase in soil. Folia Pomer. Univ. Technol. Stetin. Agric. Aliment. Pisc. Zootech. 296(23), 91-96.

32. West S.D., Yeh L.T., Shwedler D.A., Tumer L.G., Thomas A.D., Duebelbeis O.O. 2000. Determination of spinosad and its metabolite in food and environmental matrices. 1. High-performance liquid chromatography with ultraviolet detection. J. Agric. Food Chem. 48, 5131-5137.

33. Xie X.M., Liao M., Huang C.Y., Liu W.P., Abid S. 2004. Effects of pesticides on soil biochemical characteristics of a paddy soil. J. Environ. Sci. 16, 252-255. 